\title{
IOT-based smart street lighting enhances energy conservation
}

\author{
Z. M. Yusoff ${ }^{1}$, Zuraida Muhammad ${ }^{2}$, Mohd Syafiq Izwan Mohd Razi ${ }^{3}$, \\ Noor Fadzilah Razali ${ }^{4}$, Muhd Hussaini Che Hashim ${ }^{5}$ \\ ${ }^{1,4}$ Faculty of Electrical Engineering, Universiti Teknologi MARA, Cawangan Johor, Malaysia \\ ${ }^{2,3,5}$ Faculty of Electrical Enigneering, Universiti Teknologi MARA, Malaysia
}

\begin{tabular}{l} 
Article Info \\
\hline Article history: \\
Received Jan 10, 2020 \\
Revised Mar 15, 2020 \\
Accepted Apr 12, 2020 \\
\hline
\end{tabular}

\section{Keywords:}

Arduino MEGA 2560

Energy wastage

ESP-01

Energy consumption

\begin{abstract}
The electricity generation cost is escalating every year while the electric energy is indispensable and increasing in demand. The resources for energy generation is also depleting due to the increasing demand of power. Thus, a system that can reduce the energy wastage and the massive expenses is essential. Street light system is one of the systems that can reduce energy consumption. The massive energy consumption from the current street light system is not efficient enough to reduce the wasted energy. By implementing an IOT-based smart street light system, the power consumption of the street light will be optimized. This system will also provide the ability to monitor input voltage for Arduino MEGA 2560 microcontroller and control the street light through IOT. The concept of this smart system is to introduce an intelligent system which can decide to switch on or off the street light according to the movement detection by using an infrared sensor module. The data will be sent to Arduino Mega 2560, which is a microcontroller that will decide to turn on or off the street light. The Wi-Fi module ESP-01 is implemented to enable the microcontroller to connect to Blynk software for monitoring and controlling purpose. The result shows that the smart street light system is expected to reduce energy consumption up to $45.48 \%$ on weekdays and $32.22 \%$ on weekends from the present street light system which uses timer system. The IOT-based Smart Street Light system also shows the condition of the street light system based on the Blynk interfaces for maintenance purpose.
\end{abstract}

Copyright $\odot 2020$ Institute of Advanced Engineering and Science. All rights reserved.

\section{Corresponding Author:}

Zakiah Mohd Yusoff, Faculty of Electrical Engineering, Universiti Teknologi MARA, Cawangan Johor, Kampus Pasir Gudang, 81750 Masai, Johor, Malaysia. Email: zakiah9018@uitm.edu.my

\section{INTRODUCTION}

The electric energy is indispensable element when it comes to human [1]. Due to limitations and rising cost of energy generation, it is becoming progressively important to direct greater efforts into optimizing electrical energy utilization [2]. Therefore, a system that efficiently uses the energy consumption is vital in order to reduce wasted energy. The energy consumption wastage is an issue to be observed [3]. As we all know, street light is a compulsory infrastructure for a city which plays a major role in traffic safety, illuminate the city street during dark hours of the day, society security, city appearance style and features [4-7].

Street lights are among the biggest energy consumer, therefore the power consumption for the street light system should be optimized to reduce the wasted energy. The existing model is observed to be inefficient leading to wastage of manpower as well as electric power [8]. The solution for current system problem to improve the efficiency and return investment of the system has been produced through analysis [9]. Other development of the nation could use the excessive expense spent on the street light [10-12]. There is also the case where the street light is still on even 
there is enough light intensity and during the day time. Research shows that the traffic rate has a low timeframe for a few streets [13]. In some area or lane, the number of vehicles passing by is very low, yet there is still an overwhelming electrical power [14]. The long hour operational time which cause a lot of electricity cost is a huge waste if it is not taken seriously. Thus, a street light system that can operate intelligently by itself is required.

These street light systems has not been optimized, hence it contributes to waste of energy consumption that costed enough money for other development. Currently, the street light system is operating based on timer as it will turn on at night and switch off in the morning. This system is inefficient as the light will be on all night even if there is no user in the area. Violation of energy conservation can be seen when the street light is still on even during the daytime when there is no requirement [15-16]. The inefficiency of street light system will result in the higher amount of energy consumption in which luminaries require high amount of energy [17]. The street light monitoring process takes time and the street light can be controlled only from the switch. The switch for a street will be at one terminal, thus it will consume time to turn the street light on or off for troubleshooting purpose or to control the street light manually. The current system consists barriers in monitoring the street light in real time. Monitoring streetlight is a tedious manual task that relies on inspection and incident reports [18]. The street light should be able to be monitored from anywhere and anytime because it could save time and manpower. The maintenance team has difficulties to troubleshoot and find the fault in the currently used street light system.

An IOT-based smart street lighting system can reduce the wasted energy. This IOT-based smart street lighting controls the street light $\mathrm{ON}$ or OFF according to the movement in the area. The public activity streams around during night time are not similar each time [19,20]. The street light will be controlled by the controller installed in the street light based on the movement on the street [19]. Therefore, with the implementation of the sensor to detect the movement in the street, the street light will intelligently decide to turn on and off the street light.

Through this system, the street light will only operate when needed instead of staying on all night. This imply that the intelligent lighting system would be collecting data of the street light and transmit it using wireless network to the master command center [21]. The smart street light will be combined with intelligence to think it self in order to save the electricity consumption and reduce wastage of energy [22]. The internet of thing (IOT) is the network of device that allows devices to interact with each other and exchange data. An IOT system can be optimized to monitor and control the street light. IOT is the network of physical devices that allows the device to interact with each other [23]. It provides remote sensing and control on devices [23]. IOT will help in connecting the internet with the lighting system [24]. This IOT system also give advantage to monitor the street light condition, such as the street light is on or off and the voltage drawn to the system. The data from the street light can be monitored anytime, anywhere through the internet [25].

Section 2 of this paper discusses the system overview of the street light with smart controller system. This section will also discuss the block diagram and schematic diagram of the developed smart street light prototype. The overall street light system flowchart and Blynk interface flow chart are also explained in Section 2. In the next section, Section 3 will discuss about the theoretical result of the smart street light system. In this section, the calibration test result and experimental result for smart street light system will be discussed.

\section{RESEARCH METHOD}

\subsection{System overview of street light with smart controller system}

The existing street light system consists of AC supply, timer system and street light. The timer is to turn on and off the street light according to the time that have been set. Presently the street light is set to turn on from 7p.m to 7a.m. and turn off for other time. Nevertheless, with this timer system, it is not effective enough to control the energy wastage. As shown in Figure 1, a smart controller system is introduced between the timer and the street light. This controller is mainly to control the usage of the street light according to the needs by users so that it can reduce the energy consumption for the street light system.

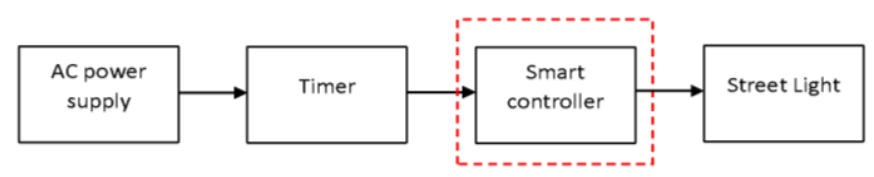

Figure 1. System overview of street light with smart controller system

\subsection{Smart controller internal architecture}

As shown in Figure 2, Arduino Mega 2560 microcontroller are used for the hardware system. Infrared sensor is used for movement detection. Voltage sensor also used to detect the voltage from the system. The relay channel is used to interface between the light and the microcontroller. Wi-Fi module, esp-01 is used to connect the system through the network. 


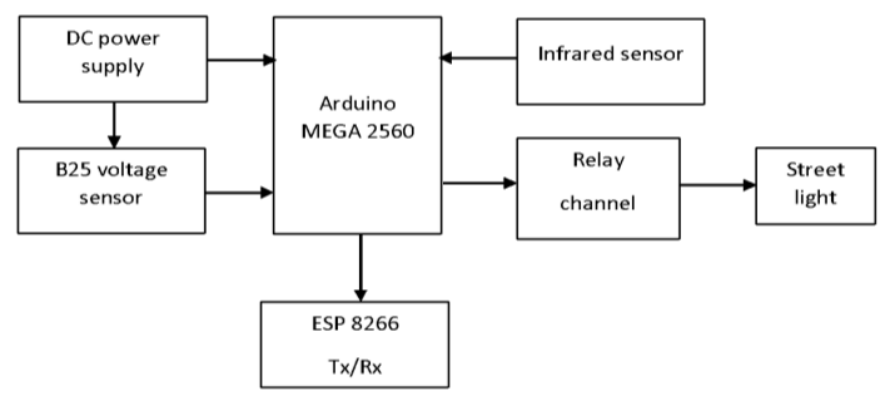

Figure 2. IOT-based smart street light controller block diagram

\subsection{Smart controller schematic diagram}

Figure 3 shows the schematic diagram of the smart controller system. The street light system used Arduino Mega 2560 as a microcontroller. In this system, the infrared sensor and voltage sensor will be the input to the microcontroller and the relay module will be the output of the system. The ESP-01 module will act as the bridge between Arduino microcontroller and Blynk application. The infrared sensor will detect the movement in the street light area. The relay module is used to manage the light on or off based on the movement in the street.

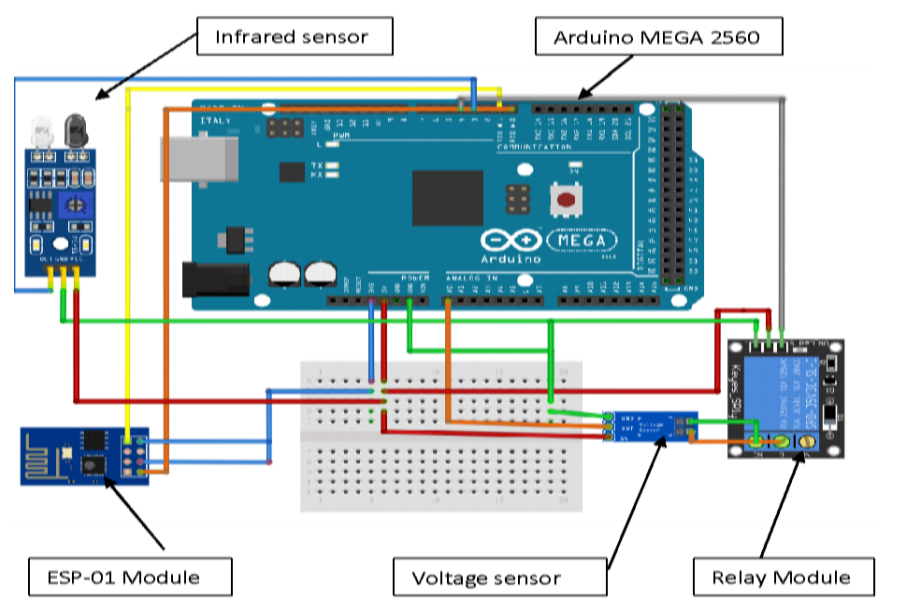

Figure 3. IOT-based smart street light controller schematic diagram

\subsubsection{Arduino MEGA 2560}

Arduino is an open source platform to create electronics project. Arduino consist of hardware which is programmable physical board and software called as Integrated Development Environment, IDE which can be used to write and upload a coding to the hardware. Arduino MEGA microcontroller consists of 54 digital input or output pin and sixteen analogue input pins. This board has more sketch memory and more RAM compared to Arduino Uno. The program coding can be upload into the board through the Arduino software in the computer. This microcontroller is easy to interface with ESP-01 Wi-Fi shield.

\subsubsection{Infrared Sensor}

The infrared sensor module is used for the prototype design of Smart Street light. Based on Figure 4, there are some components installed inside the infrared module such as infrared transmitter and receiver to transmit and receive the infrared ray. There is also variable resistor that is used to control the distance of transmitted infrared ray. The maximum distance that can be varies is $16 \mathrm{~cm}$. The power indicator is to indicate the module is working and the switch instructs is to indicate if the module detect an object within the range set. Infrared sensor produces a digital signal as the output. This digital system makes it very easy to interface with the Arduino board. The digital system will only produce two value which is ' 1 ' or ' 0 ' as output or input value. The board has been included with potentiometer that can adjust the distance of the infrared light transmit. The maximum range that can be covered by infrared transmitter is $16 \mathrm{~cm}$. This sensor is connected to the digital pin of Arduino mega 2560. Hence, the sensor will give digital value as a result, ' 1 ' if the sensor detect object and ' 0 ' if there is no object detected. 


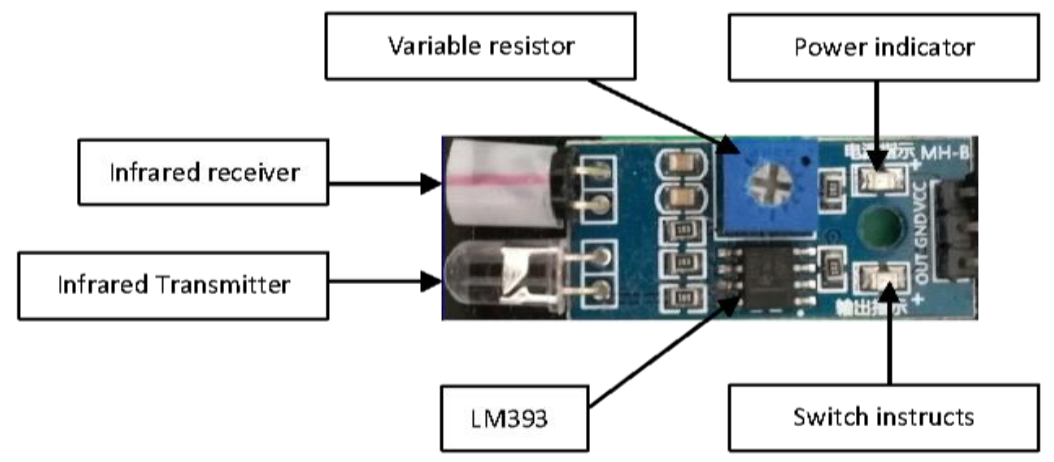

Figure 4. Infrared sensor module

\subsubsection{B25 voltage sensor}

The Arduino Mega 2560 analog input only limited to 5V. This module uses the current divider rule using R1 and R2 which having values of $30 \mathrm{~K} \Omega$ and $7.5 \mathrm{~K} \Omega$ resistor respectively. Figure 5 show the voltage sensor schematic diagram that consist of two resistor R1 and R2 which are $30 \mathrm{~K} \Omega$ and $7.5 \mathrm{~K} \Omega$ respectively. The $25 \mathrm{~V}$ will be represented by 1024 as Arduino pin have 10-bit analogue to digital converter. As $240 \mathrm{~V}$ will be used for the street light input, a stepdown transformer will be implemented to stepdown the voltage to $12 \mathrm{~V}$.

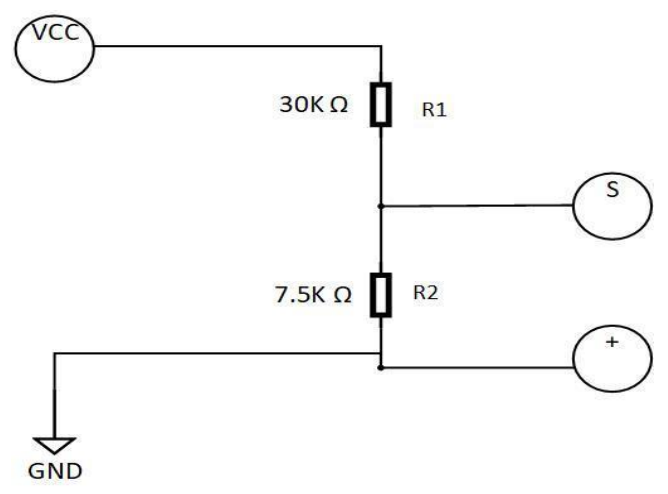

Figure 5. IOT-based smart street light controller schematic diagram

\subsection{Smart controller hardware design}

The street light prototype design is only using a small scale design. The measurement used in this design is in centimeter $(\mathrm{cm})$. One side of the street is to be considered for the prototype. Two LED bulb $1.8 \mathrm{KW}$ will be used as the street light. The distance between the LED and infrared sensor is $15 \mathrm{~cm}$. Table 1 shows the distance of the sensor to light and light to light for prototype is $15 \mathrm{~cm}$ compared to real distance which is $35 \mathrm{~cm}$. The width of the prototype is $10 \mathrm{~cm}$ representing the real distance that is $4 \mathrm{~m}$. The street light prototype design is shown as in Figure 6.

Table 1. IoT-based smart street light prototype measurement

\begin{tabular}{ccccc}
\hline Measurement & Sensor 1 to light 1 & Light 1 to light 2 & Sensor 2 to light 2 & Sensor to Outer line \\
\hline Prototype distance $(\mathrm{cm})$ & 15 & 15 & 15 & 10 \\
Real distance (meter) & 35 & 35 & 35 & 4.5 \\
\hline
\end{tabular}

\subsection{Flow chart of overall smart street light system}

Figure 7 show the system flowchart of the IOT-based smart street lighting. Firstly, the voltage sensor will proceed to read the voltage value of the system. When both sensors have completed the process, the infrared sensor will send the data ' 0 ' or ' 1 ' to Arduino mega. If there is no movement in the area, the infrared sensor will send ' 0 ' and when there is movement detected, it will send ' 1 ' to the microcontroller. 
If there is movement and the microcontroller will receive the ' 1 ' data, the relay will be triggered to switch on the street light. However, if the microcontroller receives the ' 0 ' data, it will trigger the relay to switch off the street light. Then the microcontroller will connect with the IOT devices through Wi-Fi connection. The data from voltage sensor will be displayed in Blynk software.

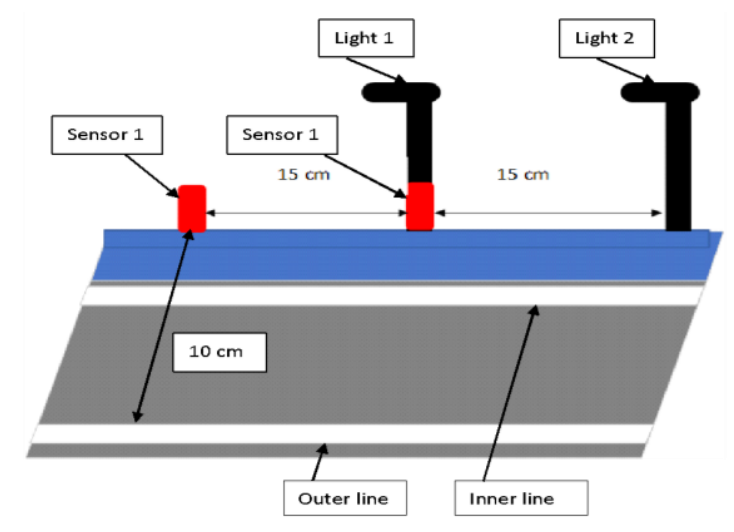

Figure 6. Infrared sensor module

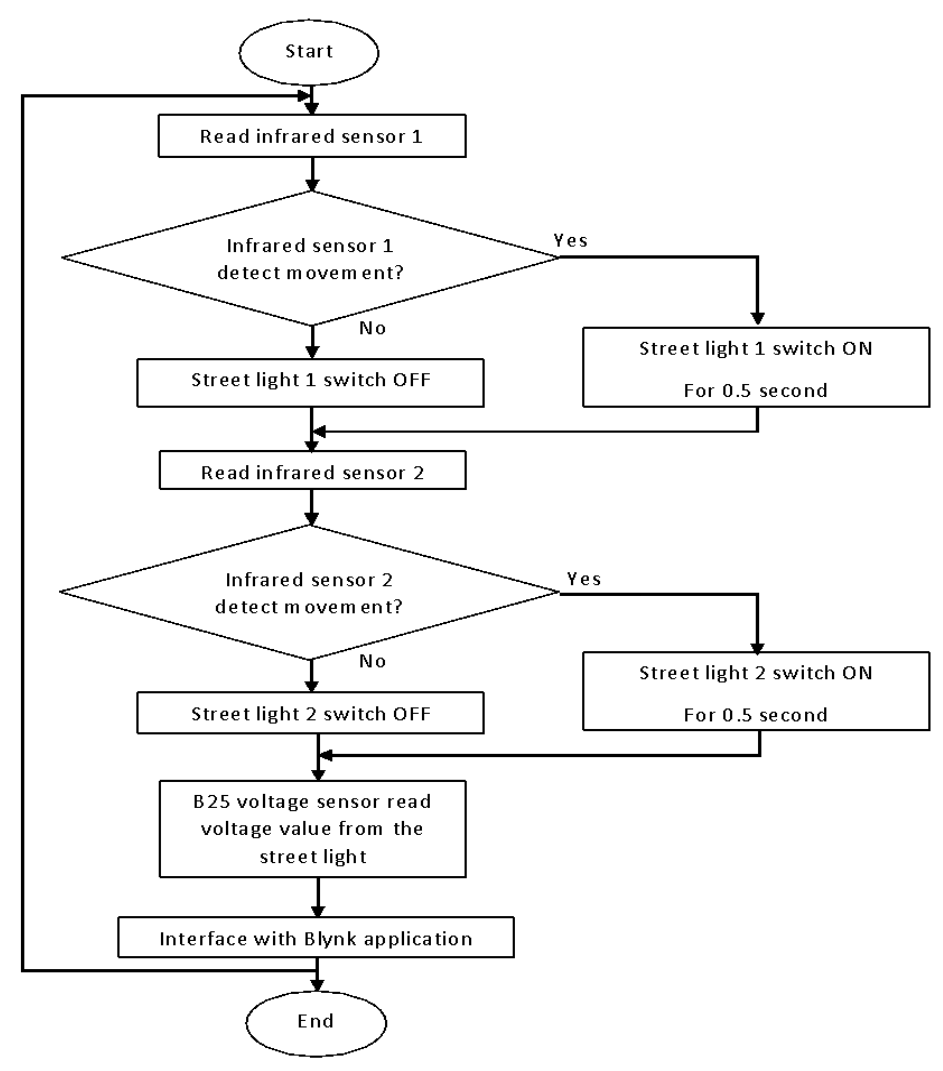

Figure 7. Flow chart of smart street light system

\subsection{Flow chart of blynk graphycal user interface}

Figure 8 show the flowchart for the Blynk application interface with Arduino MEGA 2560 microcontroller. The mocrocontroller will classify infrared sensor high if there is movement detected by infrared sensor and low if there is no movement detected by infrared sensor. Then it will sent data to Blynk application whether the infrared sensor is high or low condition. The D2 and D3 indicates infrared sensor 1 and infrared sensor 2 respectively. After that, microcontroller will sent the value of current voltage to be displayed by Blynk application through gauge widget. 


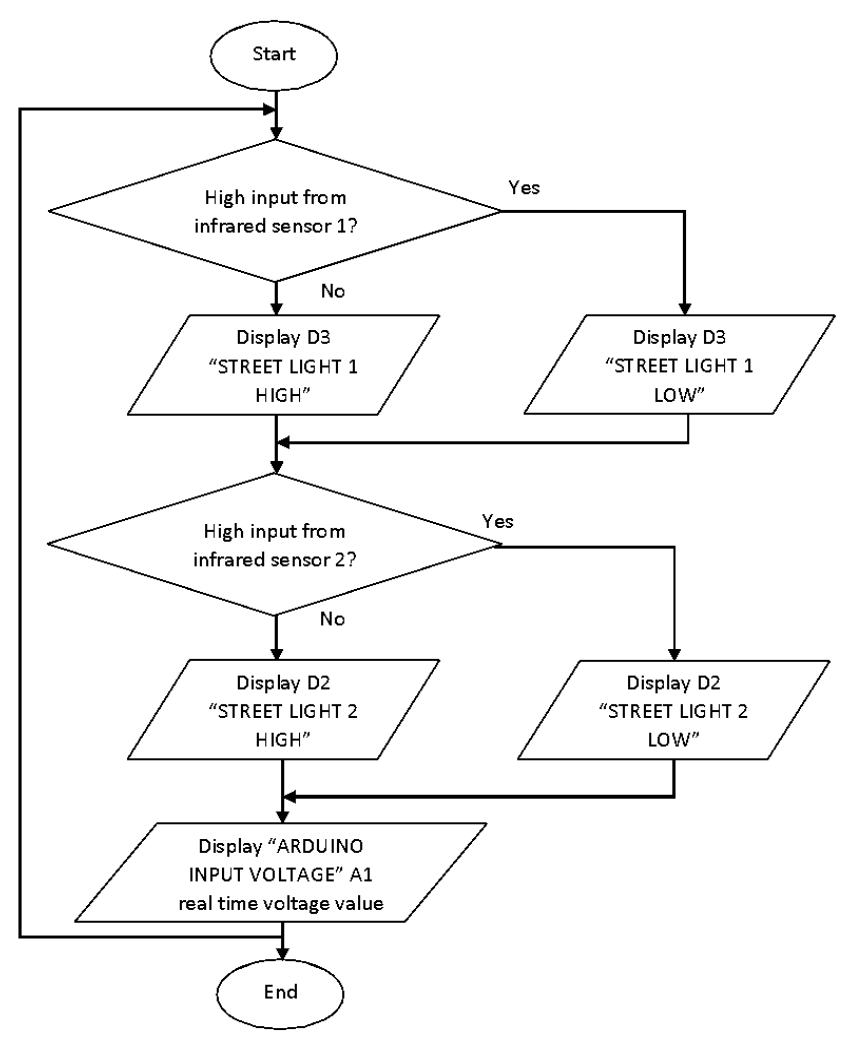

Figure 8. Flow chart of blynk graphycal user interface

\section{RESULTS AND DISCUSSION}

\subsection{Existing Street light power consumption}

Based on Figure 9, we can see that the energy consumption of the present street light system is at $100 \%$ in one day. Voltage sensor calibration as shown in Figure 10.

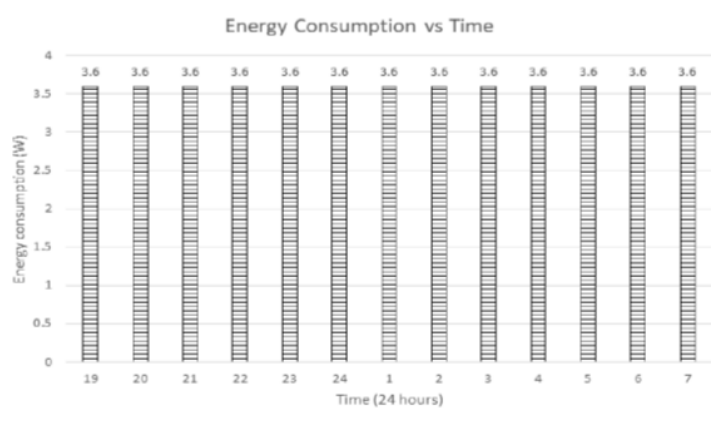

Figure 9. Energy consumption vs operating time of prototype street light

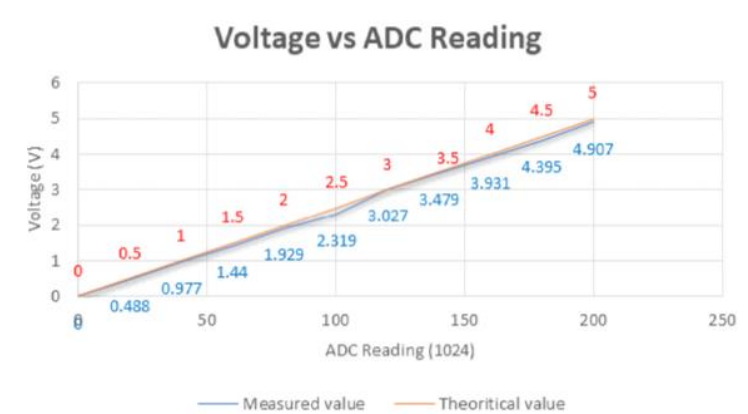

Figure 10. Voltage sensor calibration

\subsection{Calibration result}

As the project uses a prototype model, a proper sensor must be used to get a good result. The selected sensor which is the voltage sensor and the infrared sensor has been calibrated. The calibration purpose is to verify the sensor accuracy.

\subsubsection{Voltage sensor}

The pin for Arduino is only limited to $5 \mathrm{~V}$, thus we consider a range of $0 \mathrm{~V}$ to $5 \mathrm{~V}$. Thus, we compare the theoretical result and the practical result as shown in the table below. The Arduino pin $0 \mathrm{~V}$ to $5 \mathrm{~V}$ is represented by value in between 0 to 1024 . 


\subsubsection{Infrared sensor}

The infrared sensor is connected to a digital pin of the Arduino. As this is the digital pin, the input of this pin will be only two which is ' 0 ' or ' 1 '. If the sensor detects an object, the sensor will give ' 1 ' as Arduino input and when there is no object detected, the sensor will give ' 0 ' for Arduino input. These Arduino pin has a $5 \mathrm{~V}$ input, thus the value also can be represented in voltage. For digital input ' 1 ' the voltage would be $5 \mathrm{~V}$ and for the digital input ' 0 ' the voltage is $0 \mathrm{~V}$. These data have been tabulated in the Table 2 . The sensor only detect object inline of the sensor.

\subsubsection{Light bulb power consumption}

Light bulb that were used in this prototype design has a $1.8 \mathrm{w}$ per hour power rating. An experiment has been run to measure the power consume from the bulb. The data has been tabulated in Table 3 . The power per hour for light bulb 1 and light bulb 2 are $1.76 \mathrm{~W} / \mathrm{h}$ and $1.69 \mathrm{~W} / \mathrm{h}$ respectively.

Table 2. Infrared sensor calibration

\begin{tabular}{ccc}
\hline Variable & Digital value & Voltage $(\mathrm{V})$ \\
\hline No Object Detected & 0 & 0.22 \\
Object Detected & 1 & 4.81 \\
\hline
\end{tabular}

Table 3. Light bulb power consumption per hour

\begin{tabular}{ccc}
\hline Variable & Speed (rpm) & Power $(\mathrm{kW})$ \\
\hline Light bulb 1 & 2 & 245 \\
Light bulb 2 & 1.9 & 245 \\
\hline
\end{tabular}

\subsection{Blynk graphical user interface}

Percentage of saved power as shown in Table 4. Blynk application was used in this system to display the voltage input for the Arduino MEGA 2560 microcontroller and also the condition of the street light. Figure 11 show the street light 1 and street light 2 is in on condition when the button 1 and 2 is in on condition. Figure 12 show that street light 1 and street light 2 is in off condition when the button 1 and 2 is in off condition. As shown in Figure 13, the street light 1 is on and the street light 2 is off when the button 1 is on and the button 2 is off. Figure 14 show that the street light 1 is off and street light 2 is on when the button 1 is in off condition and button 2 is on condition. The condition of street light will show 'HIGH' if the street light is off and 'LOW' when the street light is on. The button 1 is to control the street light 1 while button 2 is to control the street light 2 . Figure 15 show the voltage supply for Arduino MEGA 2560 is 12V. Based on these interfaces we can detect the street light is in good condition or otherwise if the street light is not synchronous with the button condition. Table 5 and Table 6 summarize the condition of the street light 1 and street light 2 during in good condition or in bad condition (system failure).

Table 4. Percentage of saved power

\begin{tabular}{cccc}
\hline Variable & Power consumed (W) & Fully optimized power (W) & Percentage of saved power (\%) \\
\hline Weekday & 24.45 & 44.85 & 45.48 \\
Weekend & 30.4 & 44.85 & 32.22 \\
\hline
\end{tabular}

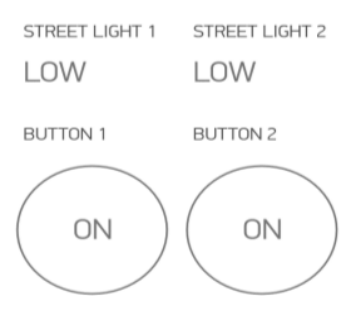

Figure 11. Light 1 and light 2 on

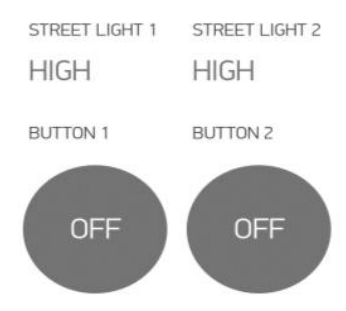

Figure 12. Light 1 and light 2 off

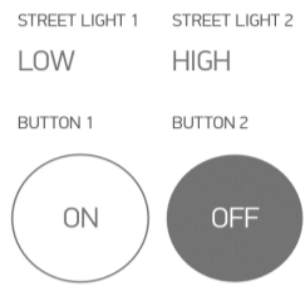

Figure 13. Light 1 on and light 2 off

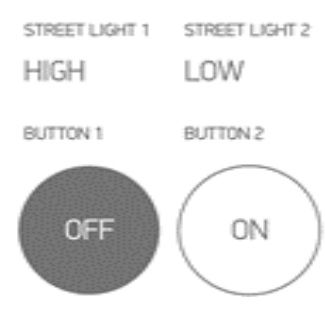

Figure 14. Light 1 on and light 2 on

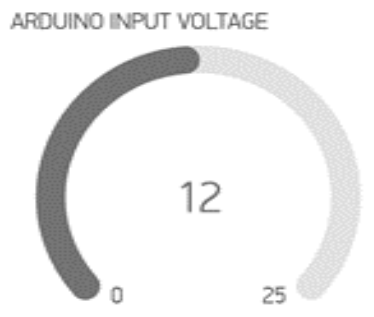

Figure 15. Arduino input voltage display 
Table 5. Street light 1 condition

\begin{tabular}{ccc}
\hline Button 1 & Street light 1 & Street light 1 condition \\
\hline 1 & 1 & Good \\
1 & 0 & Bad \\
0 & 0 & Good \\
0 & 1 & Bad \\
\hline
\end{tabular}

Table 6. Street light 2 condition

\begin{tabular}{ccc}
\hline Button 2 & Street light 2 & Street light 2 condition \\
\hline 1 & 1 & Good \\
1 & 0 & Bad \\
0 & 0 & Good \\
0 & 1 & Bad \\
\hline
\end{tabular}

\subsection{IOT-based smart street lighting power consumption}

The experiment was run for the IOT-based Smart Street Light prototype system. Analysis were done during the weekdays and weekends.

\subsubsection{Weekday}

This section is considering the street user during the weekdays. As shown in Figure 16 the number of vehicles decrease significantly at midnight and increasing after 0300 hours as people started going to work. From this data, the power consumption for the IOT-based smart street light system on weekdays were plotted as in Figure 17. From the table, we can see that the number of vehicles that uses the street is slightly lower than during the weekend. By using the IOT-based smart street light system, the percentage of power that can be saved during weekday are $45.48 \%$.

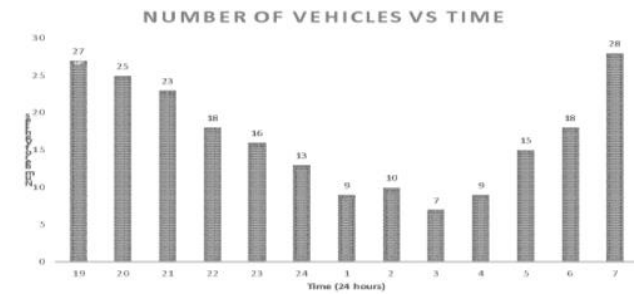

Figure 16. Number of vehicles on weekday

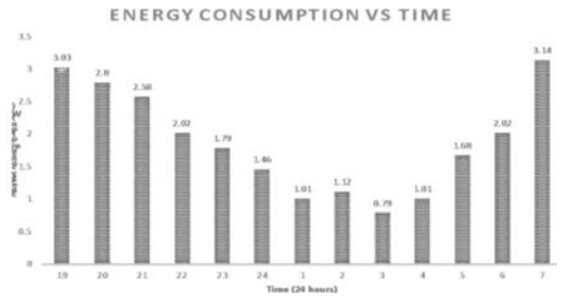

Figure 17. Energy consumption during weekday

\subsubsection{Weekend}

This section is considering the street user during the weekends. As shown in Figure 18, for 1900 until 0200, the number of vehicles maintain in range of 25 to 30 vehicles per hour, after that, the number of vehicles decrease significantly. From the data that has been collected, the power consumption for the IOT-based smart street light system on weekend were plotted as in Figure 17. The percentage of power that can be saved during weekend as the implementation of the IOT-based smart street light system is $32.22 \%$. Energy consumption during weekend as shown in Figure 19.

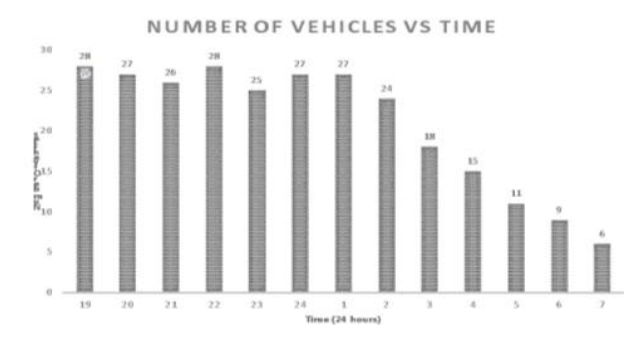

Figure 18. Number of vehicles on weekend

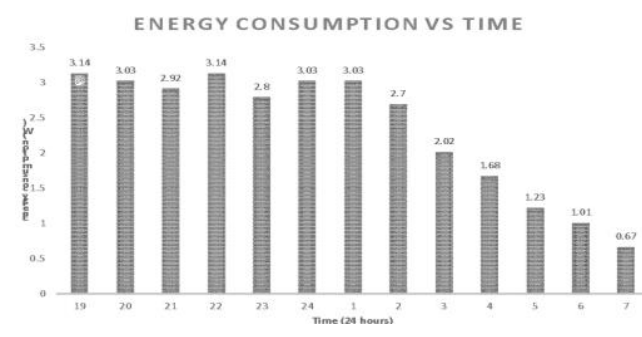

Figure 19. Energy consumption during weekend

\section{CONCLUSION}

In general, the IOT-based Smart Street Light System has been successfully modelled and controlled using Arduino MEGA 2560 microcontroller. Based on the prototype design and experiment, this IOT-based Smart Street Light System prototype has saved the energy consumption by $45.48 \%$ on weekdays and $32.22 \%$ on weekends, thus this system maintained the wasted energy below $100 \%$ usage. This system also successfully implemented the infrared sensor to detect movement on the street light as the input for the Arduino microcontroller. It was found that the IOT system perform very well and gave an accurate display of the street light system. The IOT-based smart street light system also controlled the street light and shows that the system successfully saved the energy depletion of a street light system by almost half of the original value. This system also successfully implemented the monitoring trough the Blynk application. Hence, with a proper system and monitoring, the energy depletion of the street light system can be managed. 


\section{ACKNOWLEDGEMENTS}

It is acknowledged that this project is supported by UiTM Kampus Pasir Gudang, and FRGS under project code: 600-IRMI/FRGS 5/3 (154/2019).

\section{REFERENCES}

[1] M. Nassereddine, J. Rizk, A. Hellany, and M. Nagrial, "Electrical Energy Management for Advance Smart Home Systems : Introduction," 2016 3rd International Conference on Renewable Energies for Developing Countries, Zouk Mosbeh, pp. 1-6, 2016.

[2] S. Priya, S. Priya, P. G. Scholar, and A. Electronics, "Automatic Street Light Control System Using Wsn Based On Vehicle Movement And Atmospheric," International Journal of Communication and Computer Technologies, vol. 05, no. 01, pp. 6-11, 2017.

[3] Abdullah, S. H. Yusoff, S. A. Zaini, N. S. Midi, and S. Y. Mohamad, "Smart Street Light Using Intensity Controller," 2018 7th International Conference on Computer and Communication Engineering (ICCCE), Kuala Lumpur, pp. 1-5, 2018.

[4] M. Swati and R. Parekar, "An Intelligent System for Monitoring and Controlling of Street Light using GSM Technology," 2015 International Conference on Information Processing (ICIP), Pune, pp. 604-609, 2015.

[5] Choosri, N., "IoT-RFID Testbed for Supporting Traffic Light Control," International Journal of Information and Electronics Engineering, vol. 5, no. 2, pp. 102-106, 2015.

[6] Janahan, S. K., Veeramanickam, M. R. M., Arun, S., Narayanan, K., Anandan, R., \& Parvez, S. J., "IoT based smart traffic signal monitoring system using vehicles counts," International Journal of Engineering and Technology (UAE), vol. 7, no. 2.21, pp. 309-312, 2018.

[7] George, A. M., George, V. I., \& George, M. A., "IOT based Smart Traffic Light Control System," 2018 International Conference on Control, Power, Communication and Computing Technologies (ICCPCCT), Kannur, pp. 148-151, 2018.

[8] M. Revathy, S. Ramya, R. Sathiyavathi, B. Bharathi, and V. M. Anu, "Automation of Street Light for Smart City," 2017 International Conference on Communication and Signal Processing (ICCSP), Chennai, pp. 0918-0922, 2017.

[9] O. Rudrawar, S. Daga, J. R. Chadha, and P. S. Kulkami, "Smart street lighting system with light intensity control using power electronics," 2018 Technologies for Smart-City Energy Security and Power (ICSESP), Bhubaneswar, pp. 1-5, 2018.

[10] B. Abinaya, S. Gurupriya, and M. Pooja, "Iot based smart and adaptive lighting in street lights," 2017 2nd International Conference on Computing and Communications Technologies (ICCCT), Chennai, pp. 195-198, 2017.

[11] Avatefipour, O., \& Sadry, F., "Traffic Management System Using IoT Technology-A Comparative Review,” 2018 IEEE International Conference on Electro/Information Technology (EIT), Rochester, MI, 2018, pp. 1041-1047.

[12] Miratunnisa, G. S., \& Budi, A. H. S., "Traffic Light Monitoring System based on NodeMCU using Internet of Things," IOP Conference Series: Materials Science and Engineering, vol. 384, no. 1, 2018.

[13] K. Tripathy, A. K. Mishra, and T. K. Das, "Smart lighting: Intelligent and weather adaptive lighting in street lights using IOT," 2017 International Conference on Intelligent Computing, Instrumentation and Control Technologies (ICICICT), Kannur, pp. 1236-1239, 2017.

[14] S. S. Badgelwar, "Survey on Energy Efficient Smart Street Light System languages like python and scratch," International Conf. I-SMAC (IoT Soc. Mobile, Anal. Cloud) (I-SMAC 2017), pp. 866-869, 2017.

[15] B. Roy, A. Acharya, T. K. Roy, S. Kuila, and J. Datta, “A Smart Street-light Intensity Optimizer,” 2018 Emerging Trends in Electronic Devices and Computational Techniques (EDCT), Kolkata, pp. 1-4, 2018.

[16] R. Kodali and S. Yerroju, "Energy efficient Smart Street light," 2017 3rd International Conference on Applied and Theoretical Computing and Communication Technology (iCATccT), Tumkur, pp. 190-193, 2017.

[17] G. Shahzad, H. Yang, A. W. Ahmad, and C. Lee, "Energy-Efficient Intelligent Street Lighting System Using Traffic-Adaptive Control," in IEEE Sensors Journal, vol. 16, no. 13, pp. 5397-5405, 2016.

[18] S. Kumar, A. Deshpande, S. S. Ho, J. S. Ku, and S. E. Sarma, "Urban Street Lighting Infrastructure Monitoring using a Mobile Sensor Platform," in IEEE Sensors Journal, vol. 16, no. 12, pp. 4981-4994, 2016.

[19] M. Kokilavani, A. M. -I. J. A. R. A. S. Technol, and U., "Smart street lighting system using IoT," International Journal of Advanced Research in Applied Science and Technology, vol. 3, no. 11, pp. 8-11, 2017.

[20] Abbas, S., Khan, M. A., Ahmed, G., \& Farooq, U., "An adaptive approach: Smart traffic congestion control system" Journal of King Saud University-Computer and Information Sciences, 2018

[21] C. B. Soh, J. J. Tan, J. W. R. Teo, W. L. Woo, and K. J. Tseng, "Intelligent Street Lighting for Smart Cities," 2018 IEEE Innovative Smart Grid Technologies-Asia (ISGT Asia), Singapore, pp. 1027-1031, 2018.

[22] Y. M. Jagadeesh, S. Akilesh, S. Karthik, and Prasanth, "Intelligent Street Lights," Procedia Technology, vol. 21, pp. 547-551, 2015.

[23] P. P. F. Dheena, G. S. Raj, G. Dutt, and S. V. Jinny, "IOT based smart street light management system," 2017 IEEE International Conference on Circuits and Systems (ICCS), Thiruvananthapuram, pp. 368-371, 2017.

[24] R. Jain, P. Gupta, A. Kaur, and P. Rakheja, "Iot Based Smart Lighting Intelligent and Weather Adaptive Lighting in Street Lights," International Journal of Computer Science Engineering (IJCSE), vol. 7, no. 4, pp. 194-196, 2018.

[25] Parkash, V. Prabu, and D. Rajendra, "Internet of Things Based Intelligent Street Lighting System for Smart City," International Journal of Innovative Research in Science, Engineering and Technology, vol. 5, no. 5, pp. 7684-7691, 2016. 